\title{
The identification and Characterisation of Transplanted Hematopoietic Stem Cells in situ.
}

\author{
S.L. Ellis, M.P. Palatsides, S. Asquith, B. Aisbett, H.M. Johnston, and S.K. Nilsson \\ Research, Peter MacCallum Cancer Centre, Locked Bag 1, A’Beckett Street, East Melbourne, \\ Victoria 8006, Australia
}

Hemopoietic stem cells (HSCs) exist in a specific microenvironment or niche within the bone marrow (BM) [1-2]. Due to the lack of a single, unique antigenic HSC marker allowing their unambiguous identification in situ, until recently, it has not been possible to define the spatial distribution of HSCs within the BM. We have now developed a novel approach using transplantation of fluorescently labelled (CFSE) cells, perfusion fixation and analysis of BM sections to track individual cells lodging in non-ablated recipients [1]. Populations enriched in HSCs ( $\mathrm{Lin}^{-} \mathrm{Sca}^{+} \mathrm{Kit}^{+}$) exhibited selective migration and lodgement in the endosteal region while, in contrast, hemopoietic cells expressing surface markers associated with lineage commitment migrated away from the endosteal region, and demonstrated high selectivity for the central BM region. Thus the distribution of transplanted hemopoietic cells within the BM is not random and closely reflects that previously defined for related cell populations in steady state adult mouse BM. In order to characterise molecules involved in this lodgement process, and the regulation of HSCs within their niche, we have developed a methodology to analyse multiple molecules on transplanted HSCs at the individual cell level using TEM.

Purified CFSE ${ }^{+}$HSCs are transplanted into nonablated recipients as previously described [1-2]. After 15 hours [2-3], the femoral BM is fixed via perfusion [see 4], femurs excised, decalcified, and embedded in a polyester low melting point wax [6] to maximise antigen retention. Longitudinal 2 um sections are cut, dewaxed, rehydrated and mounted in antifade before examination using a dual band pass filter (Ex: DBP 485/20 + 578/14, BS: DFT 500 + 600, EM: BP 515-540 + LP610).

$\mathrm{CFSE}^{+}$cells are photographed and classified as 'endosteal' (fig 1A) or 'central' (fig 1B)[1-2]. In order to locate these cells post-labeling, a BM 'map' is made by inverting the images in Photoshop and overlaying them onto a montage of BM section (fig 2). $\mathrm{CFSE}^{+}$cells are labeled for TEM analysis by blocking free aldehydes in $50 \mathrm{mM}$ glycine and proteins in $5 \% \mathrm{BSA}, 0.1 \%$ cold water fish skin gelatin in PBS, and incubating with mouse anti-FITC antibody conjugated to ultrasmall gold. The gold is silver enhanced (Aurion R-Gent SE-LM kit) to clearly identify donor HSCs (fig 3B). Sections are dehydrated, embedded in resin and "popped off" the slide as per de Masy Jensen and di Sant'Agnese [5]. Areas of interest are trimmed, $70 \mathrm{~nm}$ sections cut with an ultra-cut S ultramicrotome (Leica) and viewed in a Hitachi H-600 TEM (fig 3C, D). Serial sections can then be immuno-labelled to identify molecules involved in HSC engraftment and regulation.

\section{References}

[1] Nilsson et al. Blood 97 (2001) 2293

[2] Nilsson et al. Blood 89 (1997) 4013

[3] Hendrikz et al. Exp Hematol. 24 (1996) 129

[4] Nilsson et al. J Histochem. Cytochem. 44 (1996) 1069

[5] De Mesy Jensen and di Sant'Agnese P. A. Ultrastructural Path. 16 (1992) 51

[6] Steedman H. F. 179 (1957) Nature 1345. 


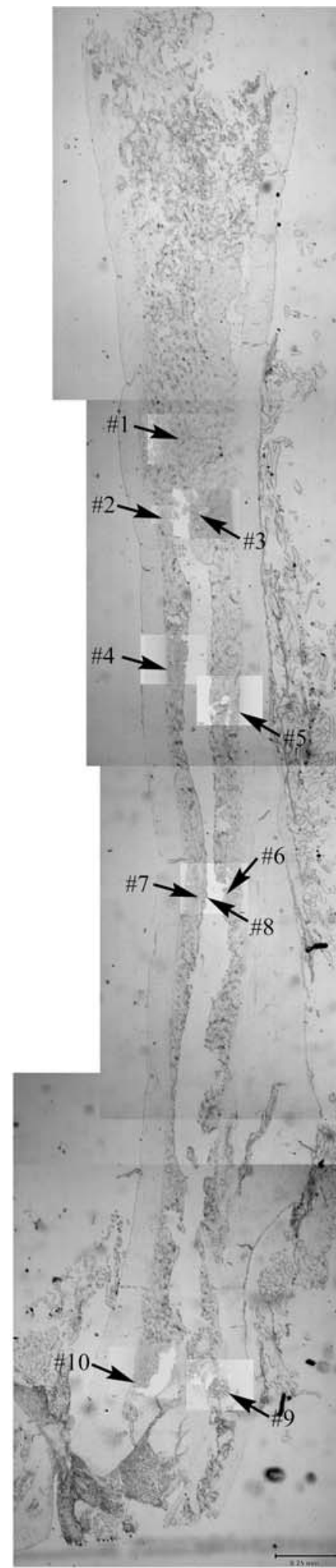

Fig 2. Montage of a BM section overlaid with images of the CFSE +ve cells
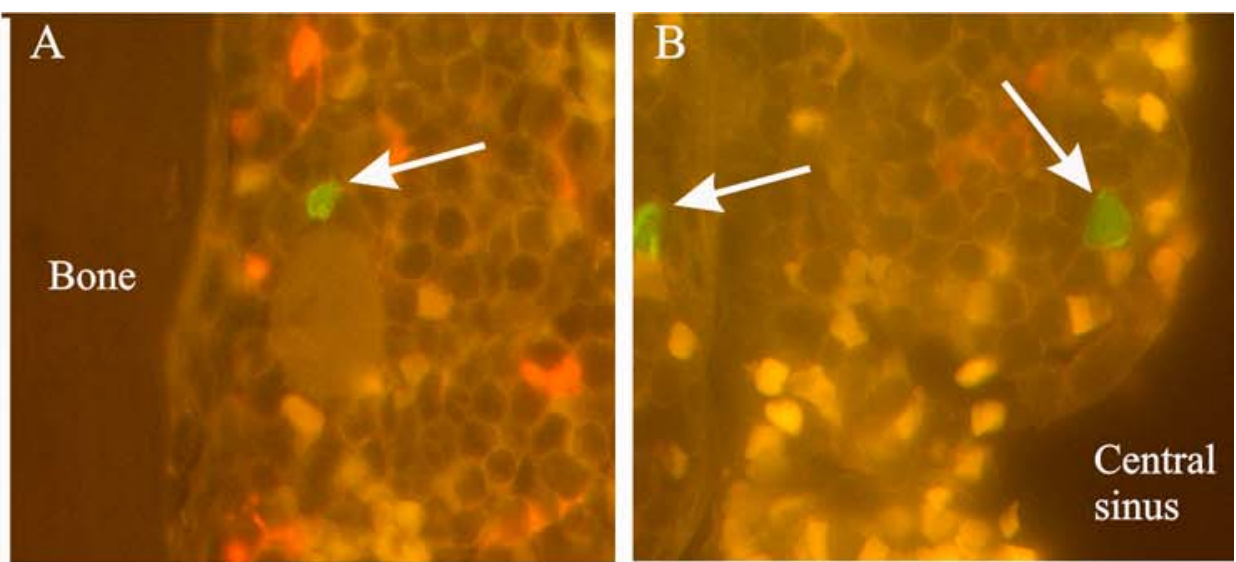

Fig 2. Spatial classification of CFSE +ve stem cells (arrows). A. Cells less then 12 cells from bone are labelled as 'endosteal'. B. 'Cental'cells.
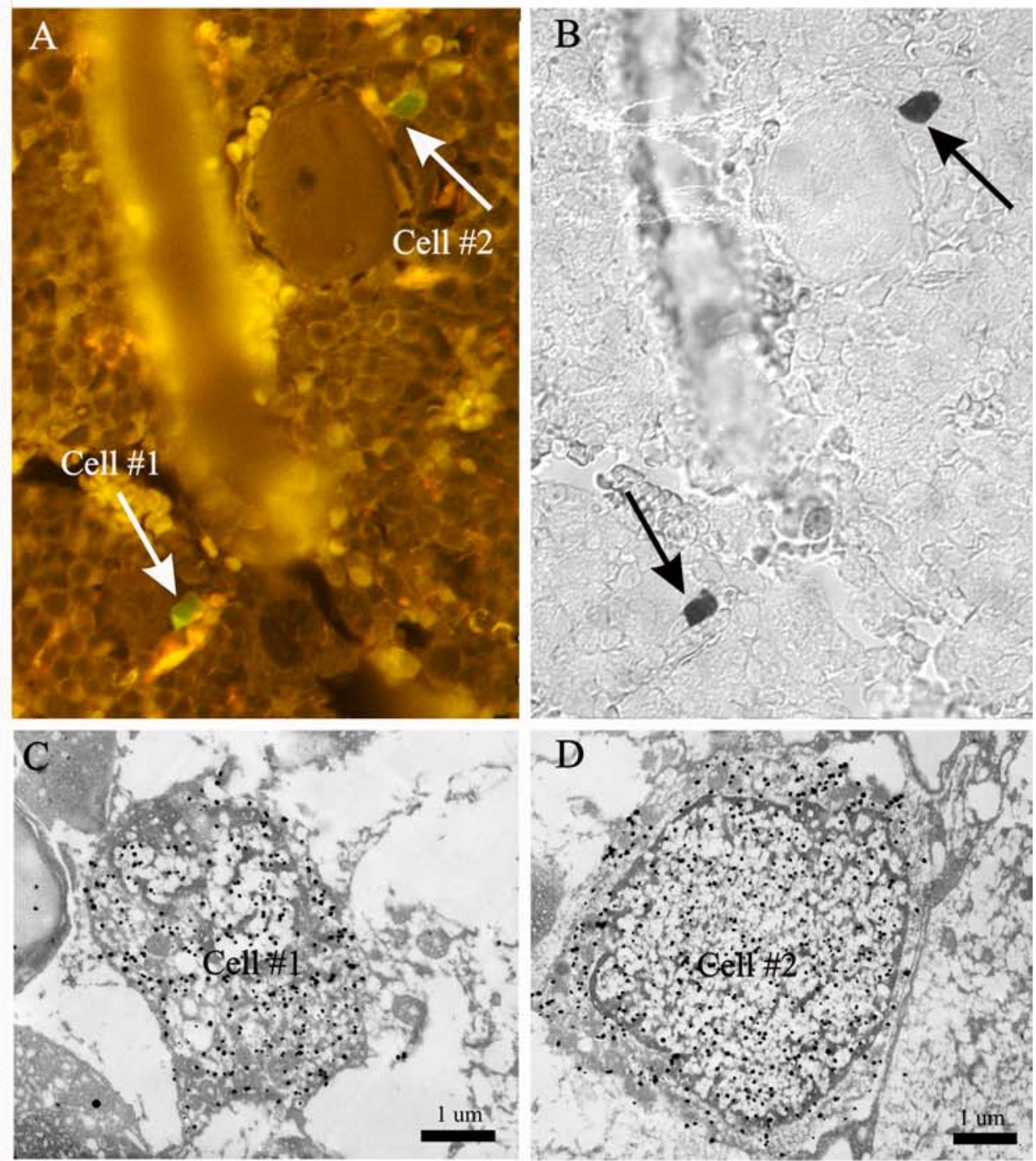

Fig 3. CFSE +ve cells are visible after silver enhancement of the gold conjugated antibody. A. CFSE +ve cells observed with epi-fluorescence. B. Silver enhanced cells visualised with DIC. C and D. The cells are clearly evident with transmission electron microscopy. 